\title{
Organic-Ruthenium(II) Polypyridyl Complex Based Sensitizer for Dye-Sensitized Solar Cell Applications
}

\author{
Lingamallu Giribabu, ${ }^{1}$ Varun Kumar Singh, ${ }^{1}$ Challuri Vijay Kumar, ${ }^{1}$ Yarasi Soujanya, ${ }^{2}$ \\ Veerannagari Gopal Reddy, ${ }^{3}$ and Paidi Yella Reddy ${ }^{3}$
}

\author{
${ }^{1}$ Nanomaterials Laboratory, Inorganic \& Physical Chemistry Division, Indian Institute of Chemical Technology, \\ Hyderabad 500607, India \\ ${ }^{2}$ Molecular Modelling Group, Indian Institute of Chemical Technology, Hyderabad 500607, India \\ ${ }^{3}$ Aisin Cosmos ReD Co. Ltd., HUDA Complex, Tarnaka, Hyderabad 500007, India
}

Correspondence should be addressed to Lingamallu Giribabu, giribabu@iict.res.in

Received 25 April 2011; Accepted 26 May 2011

Academic Editor: Surya Prakash Singh

Copyright ( $\odot 2011$ Lingamallu Giribabu et al. This is an open access article distributed under the Creative Commons Attribution License, which permits unrestricted use, distribution, and reproduction in any medium, provided the original work is properly cited.

\begin{abstract}
A new high molar extinction coefficient organic-ruthenium(II) polypyridyl complex sensitizer (RD-Cou) that contains $2,2^{\prime}, 6,6^{\prime}$ tetramethyl-9-thiophene-2-yl-2,3,5,6,6a,11c-hexahydro $1 \mathrm{H}, 4 \mathrm{H}$-11 oxa-3a-aza-benzoanthracene-10-one as extended $\pi$-conjugation of ancillary bipyridine ligand, 4,4' -dicaboxy-2,2': $6^{\prime}, 2^{\prime \prime}$-bipyridine, and a thiocyanate ligand in its molecular structure has been synthesized and completely characterized by CHN, Mass, ${ }^{1} \mathrm{H}-\mathrm{NMR}$, UV-Vis, and fluorescence spectroscopies as well as cyclic voltammetry. The new sensitizer was tested in dye-sensitized solar cells using a durable redox electrolyte and compared its performance to that of standard sensitizer Z-907.
\end{abstract}

\section{Introduction}

The increasing demand for power supply as well as environmental concern for the consumption of fossil fuel have triggered a greater focus all over the world on renewable energy sources over the past decades [1]. In this context, solar energy appears to be very attractive alternate: covering $0.16 \%$ of the earth with $10 \%$ efficient solar conversion systems would provide power nearly twice the world's consumption rate of fossil energy [2]. For this reason, dye-sensitized solar cells (DSSC) have emerged as one of the most promising candidates because of its cost-effective manufacturing, a respectable high efficiency and a remarkable stability under the prolonged thermal and light soaking dual stress among various photovoltaics [3-5]. A typical DSSC system consists of a nanocrystalline semiconductor that adsorbs a sensitizer on its surface, a Pt-counter electrode, and a redox mediator. The photosensitizer plays a crucial role in achieving higher photoconversion efficiency and has been actively studied globally. A wide variety of sensitizers have been studied for DSSC that includes various metal complexes, organic molecules, porphyrins, and phthalocyanines and so forth [6-9]. But only ruthenium-based sensitizers could have marked their way towards commercialization because of their high photoconversion efficiencies. The most successful ruthenium charge transfer sensitizers employed in such cells are $b i s$ (tetrabutylammonium)-cis-di(thiocyanato)- $N, N^{\prime}$-bis (4-carboxylato-4'-carboxylic acid-2,2'-bipyridine)ruthenium(II) (the N719 dye) and trithiocyanato $4,4^{\prime} 4^{\prime \prime}$-tricaboxy-2,2': $6^{\prime}, 2^{\prime \prime}$-terpyridine ruthenium(II) (the black dye) produced solar-energy-to-electricity conversion efficiencies $(\eta)$ of $>11 \%$ [10-13]. The high efficiency of these complexes are attributed to its suitable ground- and excited-state energy levels with respect to the nanocrystalline $\mathrm{TiO}_{2}$ conduction band energy and matching redox properties with the $\mathrm{I}^{-} / \mathrm{I}_{3}{ }^{-}$ redox couple. However, the durability of these devices is very low due to the leakage of volatile liquid redox electrolytes. In order to improve the device durability, one has to replace the liquid redox electrolyte with either quasisolid or solid redox electrolyte. Gratzel and coworkers have designed an alternative amphiphilic ruthenium(II) complex (Z-907) in order to suit for quasisolid redox electrolytes $[14,15]$. 


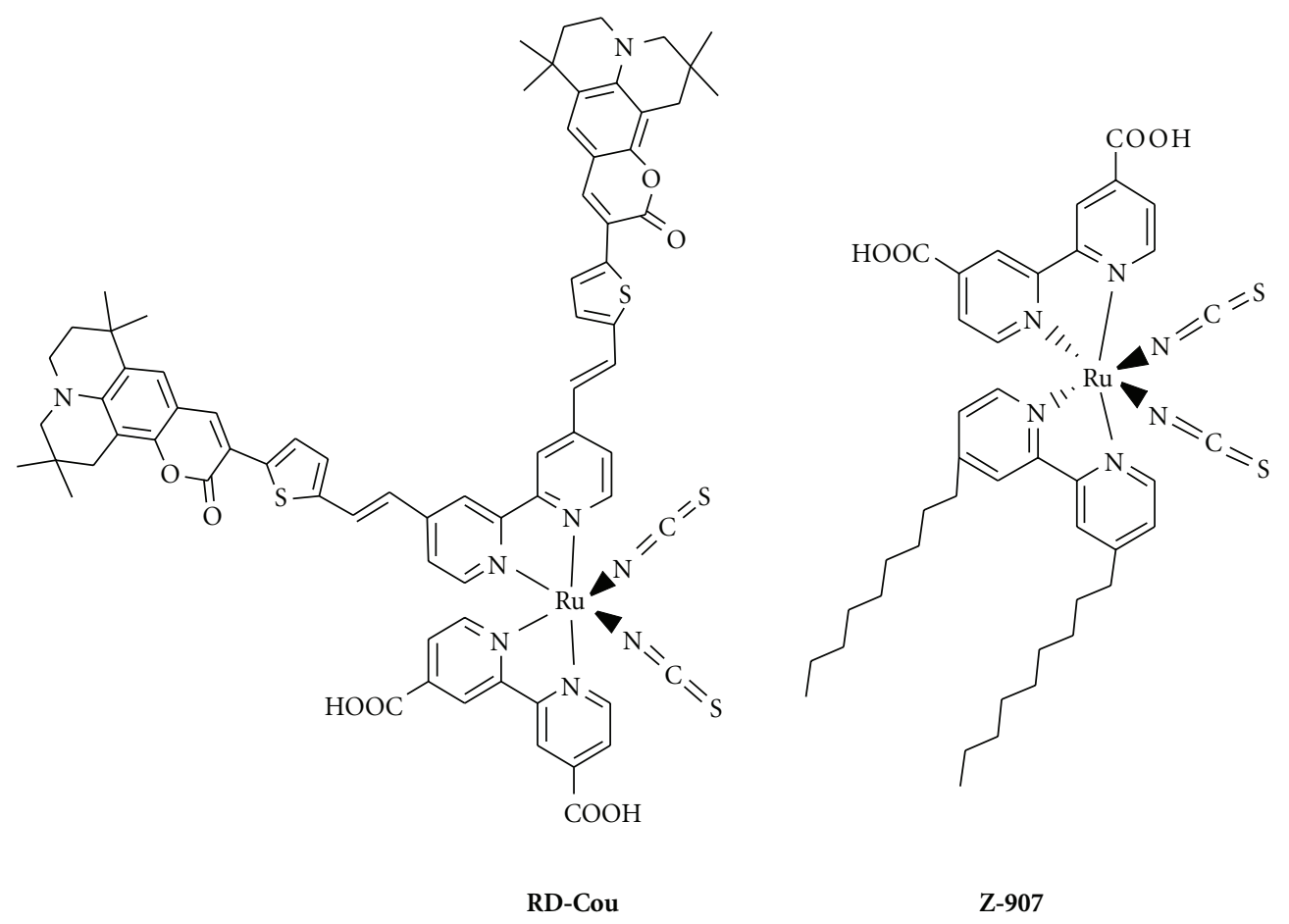

Figure 1: Molecular structure of RD-Cou and Z-907.

In order to further improve the efficiency of DSSC devices based ruthenium(II) sensitizers one has to improve its near-IR absorption because of its absorption maxima restricted at around $550 \mathrm{~nm}$ and more over the molar absorption coefficient of ruthenium(II) complexes are low causing use of thicker $\mathrm{TiO}_{2}$ layers which further has disadvantage of achieving higher open circuit potential. Hence, research to find optimum ruthenium-based sensitizers has been focused primarily on enhancing the molar absorption coefficient as well as broadening of the metal-to-ligand charge transfer band. For this reason, Gratzel and coworkers have increased the molar extension coefficient of ruthenium(II) complexes by introducing extended $\pi$-conjugation concept in the molecular structure [16, 17]. We have also adopted the same concept for increasing the molar extinction coefficient and reported a few ruthenium(II) polypyridyl complexes [18-20]. Thiophene-derived units are good candidates for increasing the conjugation length of the ancillary ligand to improve the light harvesting ability of a ruthenium complex [21]. In surge, we have synthesized a new type of ruthenium sensitizer consisting of a donor (hole transport) Coumarin moiety bridged to the pyridyl groups by thiophene which resulted in extended $\pi$-conjugation and broadening in the metal-to-ligand charge transfer transition. The reason that we have chosen Coumarin as an organic moiety is that it has absorption in $450 \mathrm{~nm}$ region where ruthenium(II) has minimum absorption and more over this class sensitizers have already shown good efficiency in DSSC devices. It is known in the literature that the introduction of donor organic moiety in ruthenium(II) polypyridyl complexes can enhance the spectral response and, therefore, conversion efficiency of the DSSC based on it [22-24]. The bipyridine carboxylic acid has been used as the anchoring media onto nanocrystalline $\mathrm{TiO}_{2}$ surface and the thiocyanate ligands to tune the redox properties of the ruthenium centre. Here in this paper, we report the synthesis, characterization, and photovoltaic studies of new ruthenium complex-based supersensitizer RD-Cou as shown in Figure 1 and compare its efficiency with that of Z-907.

\section{Experimental}

2.1. Synthesis. 4,4'-dicarboxylic acid-2,2' -bipyridine (Bpyacid), 4,4' -diethyl ester phosphonate-2,2' -bipyridine (Bpyphosphonate), and formyl coumarin (Cou-S-CHO) were synthesized according to the procedures reported in the literature $[25,26]$.

2.1.1. Synthesis of Bpy-Cou (L). The ligand Bpy-Cou (L) was synthesized by using Wittig-Horner reaction [27]. NaH (26 mg, $1.09 \mathrm{mmol}$ ) was added to a solution of Bpy-phosphonate (100 mg, $0.21 \mathrm{mmol}$ ) and Cou-S-CHO (196 mg, $0.48 \mathrm{mmol}$ ) in $150 \mathrm{~mL}$ of dry tetrahydrofuran (THF). The resulting reaction mixture was refluxed overnight under nitrogen atmosphere. The reaction mixture was allowed to cool to room temperature and then filtered. The filtrate is concentrated, and the obtained solid is washed with methanol and dried to get the desired product in pure form of $75 \%$ yield. Elemental analysis of Anal. Calcd. for $\mathrm{C}_{60} \mathrm{H}_{58} \mathrm{~N}_{4} \mathrm{O}_{4} \mathrm{~S}_{2} \%$ (963): C, 74.81; H, 6.07; N, 5.82. Found: C, 74.90; $\mathrm{H}, 6.05 ; \mathrm{N}, 5.85 .{ }^{1} \mathrm{H} \mathrm{NMR}\left(\mathrm{CDCl}_{3}\right): \delta, \operatorname{ppm} 9.08$ $(\mathrm{d}, 2 \mathrm{H}), 8.6(\mathrm{~d}, 2 \mathrm{H}), 8.4(\mathrm{~s}, 2 \mathrm{H}), 7.9(\mathrm{~d}, 2 \mathrm{H}), 7.7(\mathrm{~d}, 2 \mathrm{H})$, 
$7.6(\mathrm{~s}, 2 \mathrm{H}), 7.25(\mathrm{~d}, 2 \mathrm{H}), 7.1(\mathrm{~d}, 2 \mathrm{H}), 6.8(\mathrm{~s}, 2 \mathrm{H}), 3.6(\mathrm{~m}$, $4 \mathrm{H}), 3.2(\mathrm{~m}, 4 \mathrm{H}), 1.9-2.1(\mathrm{~m}, 4 \mathrm{H}), 1.4(\mathrm{~m}, 4 \mathrm{H}), 0.9-1.3(\mathrm{~s}$, 24H). ESI-MS: $m / z 962[\mathrm{M}]^{+}$. UV/Vis., (ethanol): $\left(\lambda_{\max }, \varepsilon\right.$ $\left.\mathrm{M}^{-1} \mathrm{~cm}^{-1}\right)=473(18,006)$.

2.1.2. $\boldsymbol{R} \boldsymbol{u}(\mathrm{L})(\boldsymbol{p}$-cymene $)(\mathrm{Cl})_{2}$. A mixture of ligand BpyCou $\mathrm{L}(0.53 \mathrm{~g}, 1.25 \mathrm{mmol})$ and $\left[\mathrm{Ru}(\mathrm{Cl})_{2}\right.$-(p-cymene $\left.)\right]_{2}$ was dissolved in ethanol: chloroform $(8: 2 \mathrm{v} / \mathrm{v})$ mixture. The resultant reaction mixture was refluxed for 4 hours under nitrogen atmosphere. Evaporation of the solvent under reduced pressure afforded the pure complex as an orange solid.

2.1.3. Synthesis of RD-Cou Dye. 4,4'-dicarboxylic acid-2,2' bipyridine ( $75 \mathrm{mg}, 0.308 \mathrm{~m} \mathrm{~mol}$ ) was dissolved in dry DMF at $80^{\circ} \mathrm{C}$. To this DMF, solution of $\mathrm{Ru}(\mathrm{L})(\mathrm{p}$-cymene $)(\mathrm{Cl})_{2}$ complex $(350 \mathrm{mg}, 0.154 \mathrm{mmol})$ was added. The reaction mixture was refluxed under nitrogen atmosphere for $4 \mathrm{~h}$ and then cools to $80^{\circ} \mathrm{C}$. To the reaction mixture was added aqueous $\mathrm{NH}_{4} \mathrm{NCS}$ (362 mg, $4.77 \mathrm{mmol}$ in $10 \mathrm{~mL}$ of $\mathrm{H}_{2} \mathrm{O}$ ) and then heated for further $2 \mathrm{~h}$ at $140^{\circ} \mathrm{C}$ and cool to room temperature. The solvent DMF was evaporated under reduced pressure, and water was added. The resulting purple solid was filtered and washed with water. The crude complex was dissolved in basic methanol (with tetrabutylammonium hydroxide (TBAOH) ) and further purified on a Sephadex LH-20 column with methanol as eluent. The main band was collected, concentrated, and precipitated with dilute acidic methanol to obtain pure desired complex. Elemental analysis of Anal. Calcd. for $\mathrm{C}_{74} \mathrm{H}_{66} \mathrm{~N}_{8} \mathrm{O}_{8} \mathrm{RuS}_{4} \%$ (1424.29): C, 62.21; $\mathrm{H}, 4.94 ; \mathrm{N}, 7.84$. Found: C, 66.70; H, 5.03; N, 7.90. ESIMS $\left(\mathrm{C}_{90} \mathrm{H}_{109} \mathrm{~N}_{9} \mathrm{O}_{8} \mathrm{RuS}_{4}\right): m / z 1670[\mathrm{M}-2 \mathrm{H}]^{+} \mathrm{IR}(\mathrm{KBr}) \mathrm{cm}^{-1}$ : 3390, 2958, 2870, 2102, 1964, 1610, 1540, 1464, 1365, 1355, 1231, 1056, 879, 784, 696. ${ }^{1} \mathrm{HNMR}\left(\mathrm{CD}_{3} \mathrm{OD}\right): 9.08$ (d, $\left.4 \mathrm{H}\right)$, $8.67(\mathrm{~d}, 4 \mathrm{H}), 8.16(\mathrm{~s}, 2 \mathrm{H}), 7.70(\mathrm{~d}, 2 \mathrm{H}), 7.25(\mathrm{~m}, 6 \mathrm{H}), 7.00$ (m, 4H), 6.96(d, 2H), $3.35(\mathrm{~s}, 4 \mathrm{H}), 3.27(\mathrm{~s}, 4 \mathrm{H}), 2.47$ (s, $4 \mathrm{H}), 1.77(\mathrm{~s}, 4 \mathrm{H}), 1.25(\mathrm{~m}, 24 \mathrm{H})$. UV/Vis (ethanol): $\left(\lambda_{\max }\right.$, $\left.\varepsilon \mathrm{M}^{-1} \mathrm{~cm}^{-1}\right)=498(16,046), 384(13,521)$.

2.2. Characterization Methods. UV-Vis spectra were measured in a $1 \mathrm{~cm}$ pathlength quartz cell using a Shimadzu model 1700 spectrophotometer. Steady state fluorescence spectra were recorded on a Spex model Fluoromax-3 spectrofluorometer using a $1 \mathrm{~cm}$ quartz cell. Solutions having optical density at the wavelength of excitation $\left(\lambda_{\text {ex }}\right) \sim 0.11$. The ${ }^{1} \mathrm{H}$ NMR spectra were recorded at $300 \mathrm{MHz}$ on a Bruker 300 Avance NMR spectrometer with X-WIN NMR software. The ${ }^{1} \mathrm{H}$ spectra were referenced to tertramethylsilane. ESI mass spectra were recorded on a Water Quattro Micro (Water Inc, USA). The infrared spectra were recorded on a Thermo Nicolet Nexus 670 FT-IR spectrophotometer. The spectra of the solid samples were recorded by dispersing the sample in Nujol mull or as $\mathrm{KBr}$ wafers. Cyclic and differential pulse voltammetric measurements were performed on a PC-controlled CH instruments model CHI 620C electrochemical analyzer. Cyclic voltammetric experiments were performed on $1 \mathrm{mM}$ dye solution in acetonitrile at scan rate of $100 \mathrm{mV} / \mathrm{s}$ using $0.1 \mathrm{M}$ tetrabutylammonium perchlorate
(TBAP) as supporting electrolyte. The working electrode is glassy carbon, standard calomel electrode (SCE) is reference electrode, and platinum wire is an auxiliary electrode. After a cyclic voltammogram (CV) had been recorded, ferrocene was added, and a second voltammogram was measured. Thermogravimetric measurements were carried out on a Mettler Toledo TGA/SDTA 851e instrument heating rate at $10^{\circ} \mathrm{C} \mathrm{min}-1$ with $10 \mathrm{mg}$ of sample under nitrogen atmosphere. DFT calculations were done for the groundstate optimization of RD-Cou at B3LYP/6-31g(d) using Gaussian 03 [28].

2.3. Device Fabrication. A screen-printed single- or doublelayer film of interconnected $\mathrm{TiO}_{2}$ particles was used as mesoporous negative electrode. A $10 \mu \mathrm{m}$ thick film of 20nm-sized $\mathrm{TiO}_{2}$ particles were first printed on the fluorinedoped $\mathrm{SnO}_{2}$ (FTO) conducting glass electrode and further coated by a $5-\mu \mathrm{m}$-thick second layer of 400 -nm-sized light scattering anatase particles. The detailed preparation procedures of $\mathrm{TiO}_{2}$ nanocrystals, pastes for screen printing, and nanostructured $\mathrm{TiO}_{2}$ film have been reported in the literature procedure [29-31]. A cycloidal $\mathrm{TiO}_{2}$ electrode $\left(\sim 0.74 \mathrm{~cm}^{2}\right)$ was stained by immersing it into a dye solution containing RD-Cou or Z907 sensitizer $(300 \mu \mathrm{M})$ in ethanol solvent overnight. After washing with ethanol and drying by air flow, a sandwich cell was prepared using the dyesensitized electrode and platinum-coated conducting glass electrode as the counter electrode. The latter was prepared by chemical deposition of platinum from $0.05 \mathrm{M}$ hexachloroplatinic acid. The two electrodes were placed on the top of each other using a thin polyethylene film ( $50 \mu \mathrm{m}$ thick) as a spacer to form the electrolyte space. The empty cell was tightly held, and edges were heated to $130^{\circ} \mathrm{C}$ to seal the two electrodes together. The active surface area of the $\mathrm{TiO}_{2}$ film electrode was ca. $0.74 \mathrm{~cm}^{2}$. The redox electrolyte was introduced into the cell through a predrilled hole of the counter electrode, which was later closed by a cover glass to avoid the leakage of the electrolyte solution. The redox electrolyte is ionic liquid electrolyte, and the composition is $0.2 \mathrm{M} \mathrm{I}_{2}, 0.5 \mathrm{M}$ guanidinium thiocyanate (GuSCN), and $0.5 \mathrm{M}$ N-methyl benzimidazole $(\mathrm{NMB}$ ) in a $65 / 35 \mathrm{v} / \mathrm{v} \%$ mixture of 1-propyl-3-methylimidazolium iodide/1-Ethyl-3methyl-imidazolium tetracyanoborate $\left[\mathrm{PMII} / \mathrm{EMIB}(\mathrm{CN})_{4}\right]$ (Z580) [15].

2.4. Photoelectrochemical Measurements. The photovoltaic performance of the dye-sensitized nanocrystalline $\mathrm{TiO}_{2}$ cells was determined using the simulator SOLARONIX SA SRIV unit Type 312. The spectral response was determined by measuring the wavelength dependence of the incident photon-to-current conversion efficiency (IPCE) using light from a 100-W xenon lamp that was focused onto the cell through a double monochromator. The current-voltage characteristics were determined by applying an external potential bias to the cell and measuring the photocurrent using a Keithley model 2420 digital source meter, and a $1000-W$ xenon lamp was used as the irradiation source. The spectral output of the lamp is set matched the AM 1.5 solar spectrum in the region of 350-750 nm (mismatch 1.9\%). 
<smiles>CCOC(=O)Cc1ccnc(-c2cc(CP(CC)OCC)ccn2)c1</smiles>

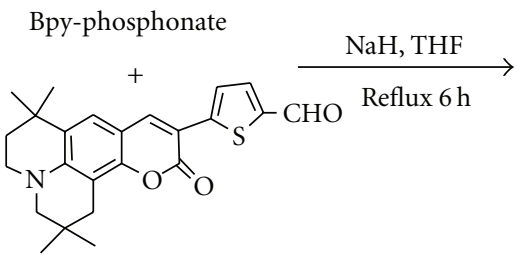

Cou-S-CHO

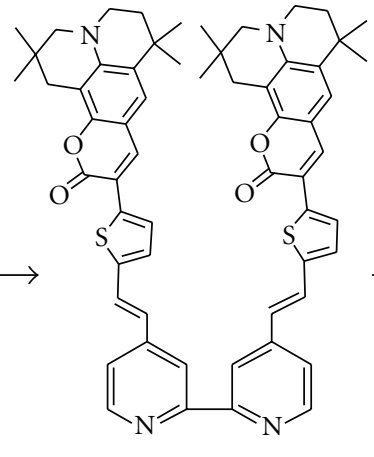

Bpy-Cou

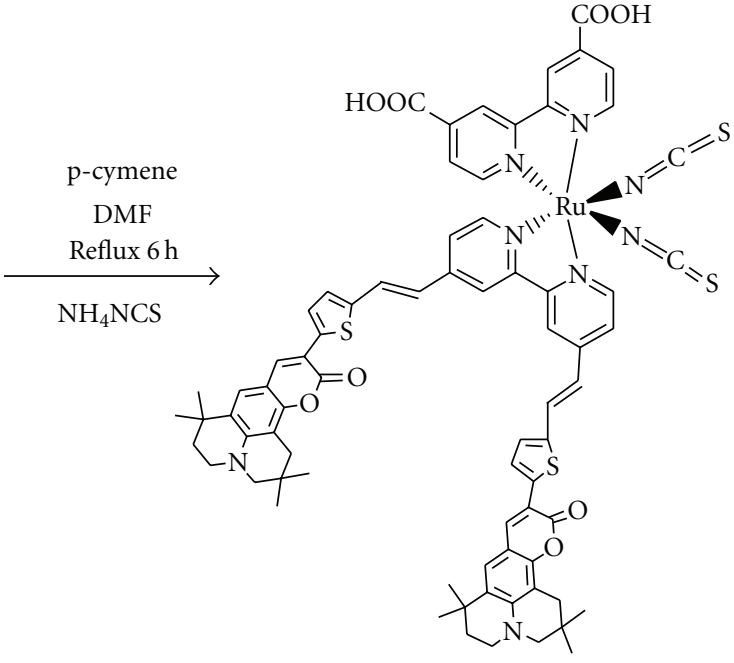

RD-Coumarin

Scheme 1

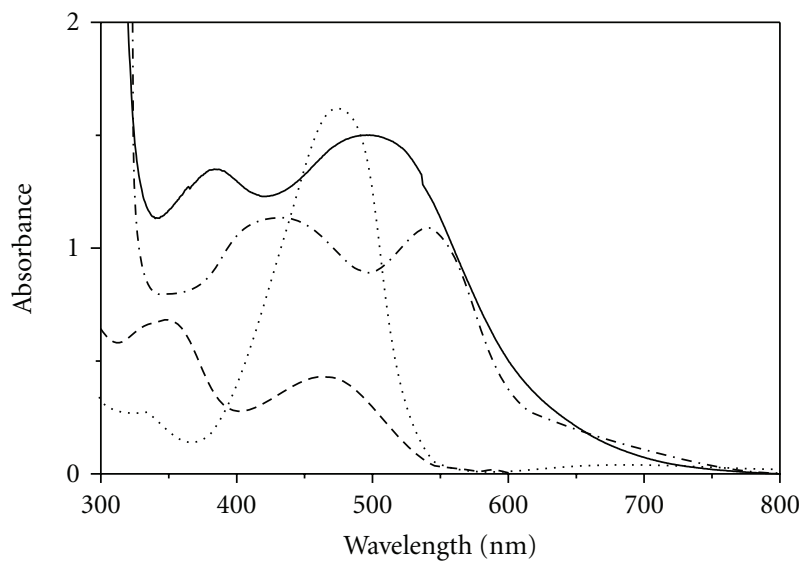

Figure 2: Electronic absorption spectra of ( $\cdots)$ Cou-S-CHO, (- - -) Bpy-Cou (L), (-) RD-Cou, and (---) Z-907 in ethanol solvent.

\section{Results and Discussion}

3.1. Synthesis and Characterization. The details of the synthetic strategy adopted for the synthesis of RD-Cou complex is shown in Scheme 1, and Z-907 was synthesized according to the literature method [14]. Both Bpy-phosphonate and Cou-S-CHO were synthesized as per the reaction procedures reported in the literature $[23,24]$. The $\mathrm{C}=\mathrm{C}$ double bond was introduced at $4,4^{\prime}$ positions of the bipyridine ligand, starting from Bpy-phosphonate with Cou-S-CHO using a Wittig-Horner reaction [27]. The ligand Bpy-Cou (L) was completely characterized by using elemental analysis, Mass, IR, and ${ }^{1} \mathrm{H}$ NMR spectroscopies. Finally, the RD-Cou complex was synthesized by refluxing $p$-cymene complex and Bpy-Cou (L) in ethanol:chloroform mixture to get the corresponding chlorocomplex. The chlorocomplex with Bpy-acid and aq. ammonium thiocyanate refluxed in DMF to get the desired complex after sephadex column purification. The complex RD-Cou was completely characterized by the elemental analysis, ESI-MS, IR, UV-Visible, and fluorescence spectroscopies as well as cyclic voltammetry. ESI-MS spectrum consists of a molecular ion peak at $1670(\mathrm{~m} / \mathrm{z})$ which corresponds to the presence of a one TBA molecule in its molecular structure.

Figure 2 shows the absorption spectra of Cou-S-CHO, Bpy-Cou (L), RD-Cou, and Z-907 in ethanol, and the corresponding data are presented in Table 1. The absorption maximum of coumarin in Cou-S-CHO is located at $470 \mathrm{~nm}$. In Z-907, the absorption maximum at $540 \mathrm{~nm}$ belongs to the metal-to-ligand charge-transfer transition in singlet manifold ( $\left.{ }^{1} \mathrm{MLCT}\right)$. The absorption maximum of RD-Cou is centered at $498 \mathrm{~nm}$ with a molar extinction coefficient of $16,046 \mathrm{M}^{-1} \mathrm{~cm}^{-1}$. From Figure 1, it is clear that the absorption of RD-Cou is very broad not like typical ruthenium(II) polypyridyl complexes. This is due to the presence of coumarin moiety in its molecular structure, which absorbs at $470 \mathrm{~nm}$. The absorption maxima of RDCou is bathochromic shift (540 nm in Z-907 to $498 \mathrm{~nm}$ in RD-Cou is hypsochromic) when compared to that of the standard sensitizer Z-907. The absorption maximum at $387 \mathrm{~nm}$ belongs to the intraligand $\pi-\pi^{*}$ transitions of bipyridine ligand. Figure 2 depicts the absorption spectra of RD-Cou adsorbed onto $6-\mu \mathrm{m}$-thick $\mathrm{TiO}_{2}$ film. The absorption features of the ruthenium complex in solution as well as when anchored onto $\mathrm{TiO}_{2}$ surface are identical except for a slight red shift in the absorption maxima due to the interaction of anchoring groups with the surface as well as further broadening [32]. The emission spectra of RDCou were measured in ethanol solvent at room temperature and are shown in Figure 3. Excitation of lower energy MLCT transition of RD-Cou sensitizer produces an emission centered at $690 \mathrm{~nm}$. The excited singlet state energy $\left(\mathrm{E}_{0-0}\right)$ of RD-Cou was calculated from the onset of absorption spectrum and was found $1.65 \mathrm{eV}$. However, the emission of RD-Cou sensitizer was quenched when adsorbed onto the $\mathrm{TiO}_{2}$ film as a consequence of electron injection from the excited state of $\mathrm{Ru}(\mathrm{II})$ into the conduction band of $\mathrm{TiO}_{2}$. 
TABLE 1: UV-visible emission and electrochemical data.

\begin{tabular}{lcccrrr}
\hline \multirow{2}{*}{ Sensitizer } & $\begin{array}{l}\lambda_{\max }, \mathrm{nm}, \\
\varepsilon\left(\mathrm{mol}^{-1} \mathrm{~cm}^{-1}\right)^{\mathrm{a}}\end{array}$ & $\lambda_{\mathrm{em}}, \mathrm{nm}^{\mathrm{b}}$ & $\mathrm{Ox}$ & $E_{1 / 2} \mathrm{~V}$ versus SCE & $E_{0-0}^{\mathrm{c}}, \mathrm{eV}^{\mathrm{d}}$ & $E_{\text {ox }}^{*}$ \\
\hline RD-Cou & $498(16.046)$ & 690 & 0.72 & -1.05 & -1.47 & 1.65 \\
Z-907 & $540(10,040)$ & 720 & 0.65 & -0.98 & -1.64 & 1.62 \\
\hline
\end{tabular}

${ }^{\mathrm{a}}$ Solvent: ethanol, Error limits: $\lambda_{\max }, \pm 1 \mathrm{~nm}, \varepsilon \pm 10 \%$. ${ }^{\mathrm{b}}$ Solvent: ethanol, $\lambda_{\max }, \pm 1 \mathrm{~nm}$. ${ }^{\mathrm{c}}$ Solvent: DMF, Error limits: $\mathrm{E}_{1 / 2} \pm 0.03 \mathrm{~V}, 0.1 \mathrm{M}$ TBAP. ${ }^{\mathrm{d}}$ Error limits: $0.05 \mathrm{eV}$.

With a view to evaluate HOMO-LUMO levels of RDCou, we have carried out the electrochemistry by adopting the cyclic and differential pulse voltammetric techniques in acetonitrile solvent using $0.1 \mathrm{M}$ tetrabutylammonium perchlorate as supporting electrolyte and compared their data with that of the standard sensitizer Z-907 in Table 1. When the potential is scanned between 0 and $1.0 \mathrm{~V}$, chemically reversible redox waves with formal potentials at 0.65 and $0.72 \mathrm{~V}$ (versus SCE) were observed, which can be attributed to the one-electron oxidation of ruthenium center in both dyes. Compared to the standard Z-907 dye, the metal center oxidation of RD-Cou is anodically shifted by $70 \mathrm{mV}$ indicating the electron-poor character of the new ligand as a result of the insertion of Coumarin moiety on extended $\pi$-conjugation. It also undergoes two reductions at -1.05 and $1.47 \mathrm{~V}$, corresponding to the one electron reduction of anchoring ligand. Furthermore, for a sensitizer in DSSC, the LUMO energy level should be compatible with the conduction band edge energy of the $\mathrm{TiO}_{2}$ photoanode $(0.80 \mathrm{~V}$ versus SCE), and its HOMO should be sufficiently low in energy to accept electrons from the $\mathrm{I}^{-} / \mathrm{I}_{3}^{-}$-based redox electrolyte $(0.2 \mathrm{~V}$ versus SCE). The excited oxidation potential of RD-Cou is $-0.93 \mathrm{~V}$ and that of standard sensitizer Z-907 is $-1.02 \mathrm{~V}$, which is above the conduction band of $\mathrm{TiO}_{2}$. In Z-907, the excited state oxidation potential is sufficiently higher than that in RD-Cou, as a result electron injection into the $\mathrm{TiO}_{2}$ conduction band is more efficient, and it should lead to a better conversion efficiency than RD-Cou.

To know the electronic distribution of RD-Cou sensitizer, we performed DFT calculations of the electronic ground state of RD-Cou sensitizer using mPW1PW91 method for the geometry optimization with LANL2DZ basis function on $\mathrm{Ru}$ and $6-31 \mathrm{~g}(\mathrm{~d})$ basis function on $\mathrm{C}, \mathrm{H}, \mathrm{N}, \mathrm{O}$ and S. As can be seen from the Figure 5, occupied orbitals HOMO, HOMO-1 and HOMO-2, have the electron delocalized over the $\mathrm{Ru}(\mathrm{II})$ metal and -NCS ligand. The LUMO, $\mathrm{LUMO}+1$, and $\mathrm{LUMO}+2$ are $\pi^{*}$ orbitals delocalized over the bipyridine carboxylic acid ligand facilitating electron injection from the excited state of RD-Cou sensitizer to the conduction band of $\mathrm{TiO}_{2}$. These results are in good agreement with other ruthenium(II) polypyridyl complexes reported in the literature $[16,17]$.

3.2. Photovoltaic Measurements. The performance of newly synthesized RD-Cou as a sensitizer with a sandwitch-type nanocrystalline $\mathrm{TiO}_{2}$ was determined from measurements on photovoltaic cells using an ionic liquid redox electrolyte, that is, $0.2 \mathrm{MI}_{2}, 0.5 \mathrm{M}$ guanidinium thiocyanate $(\mathrm{GuSCN})$, and $0.5 \mathrm{M} \mathrm{N}$-methyl benzimidazole $(\mathrm{NMB})$ in a $65 / 35 \mathrm{v} / \mathrm{v} \%$

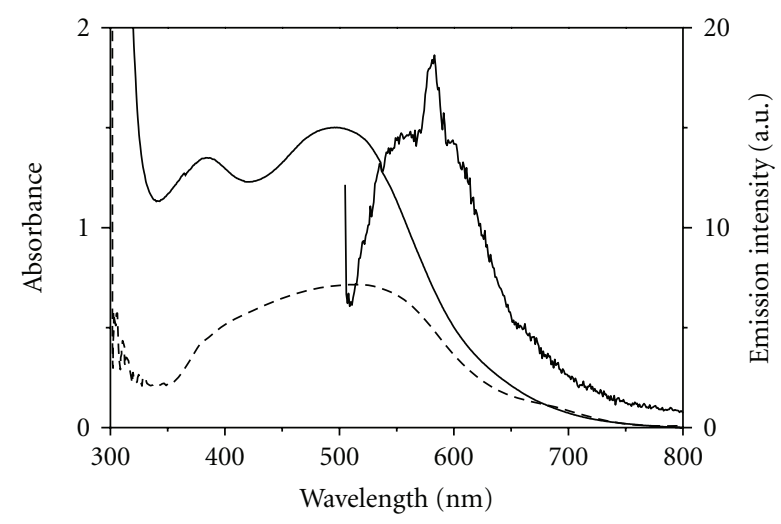

FIgURE 3: Absorption (-) and emission spectra in ethanol and absorption (- - ) spectra adsorbed onto a $6 \mu \mathrm{m}$ thick $\mathrm{TiO}_{2}$ film of RD-Cou.

mixture of 1-propyl-3-methylimidazolium iodide/1-Ethyl-3methyl-imidazolium tetracyanoborate $\left[\mathrm{PMII} / \mathrm{EMIB}(\mathrm{CN})_{4}\right]$ (Z580) and compared its performance with that of standard sensitizer Z-907 under similar test cell conditions. The additive guanidinium thiocyanate in redox electrolyte is to improve the $V_{\text {oc }}$ by reducing the dark current [33]. We assume that in our case, also guanidinium thiocyanate in Z580 redox electrolyte is responsible for improvement in $V_{\mathrm{oc}}$. 1-Ethyl-3-methylimidazolium tetracyanoborate $\left(\mathrm{EMIB}(\mathrm{CN})_{4}\right)$ is an ionic liquid of a low viscosity $(19.8 \mathrm{cP}$ at $20^{\circ} \mathrm{C}$ ) and high chemical and thermal stability. By using this redox electrolyte with this composition, Gratzel and coworkers have observed an efficiency of 6.4\% [15]. Figure 5 illustrates the photocurrent action spectra of RD-Cou and Z-907, where the incident monochromatic photon-tocurrent conversion efficiencies (IPCE) values are plotted as a function of excitation wavelength. The IPCE was calculated according to the following equation:

$$
\operatorname{IPCE}(\%)=1240\left(\frac{J_{\mathrm{sc}}}{\lambda_{\phi}}\right) \times 100,
$$

where $\lambda$ is the wavelength $(\mathrm{nm}), J_{S C}$ is the photocurrent density under short circuit conditions $\left(\mathrm{mA} / \mathrm{cm}^{2}\right)$, and $\phi$ is the incident radiative flux $\left(\mathrm{mW} / \mathrm{cm}^{2}\right)$. We have observed IPCE values of 60 and 68\% using RD-Cou and Z-907 sensitizers, respectively. From Figure 4, it is clear that the photocurrent action spectrum resembles the absorption spectra except for a slight red shift by ca. $10 \mathrm{~nm}$ in both RDCou and Z-907. The photoresponse of thin films displays a broad spectral response covering the entire visible spectrum up to $800 \mathrm{~nm}$ in both the sensitizers. 


\section{RD-Coumarin}
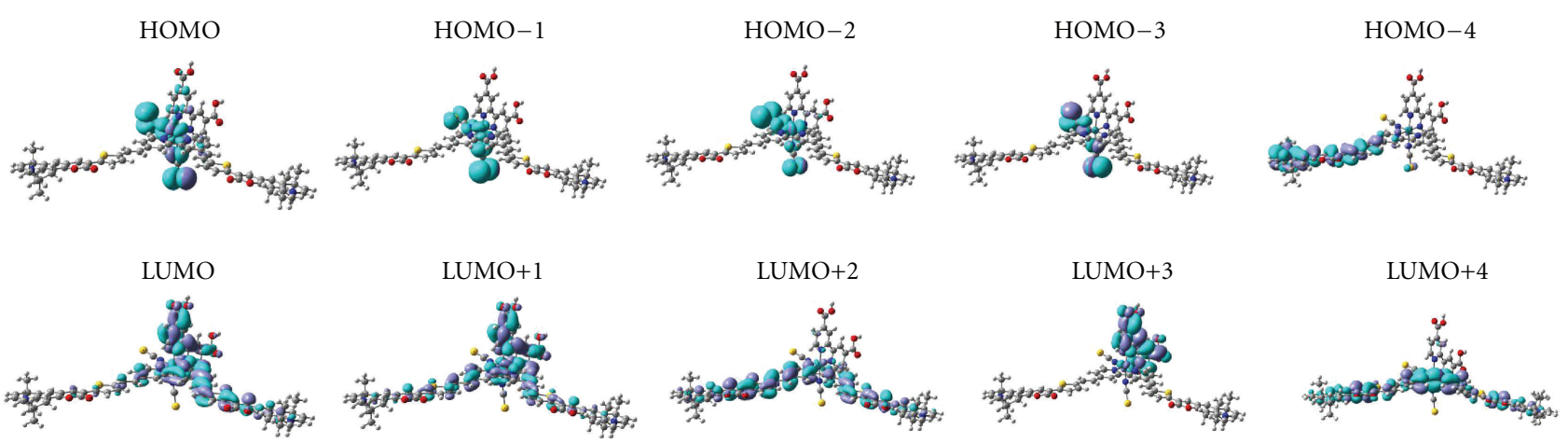

Figure 4: Molecular orbital spatial orientation of RD-Cou.

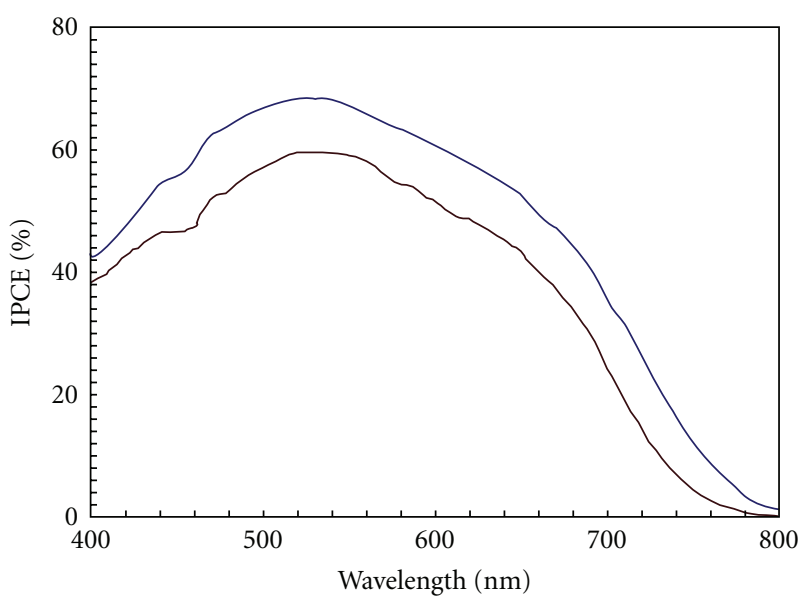

Figure 5: Photocurrent action spectra of (brown line) RD-Cou and (blue line) Z-907 using Z-580 redox electrolyte.

TABLE 2: Photovoltaic performance of RD-Cum and Z-907 .

\begin{tabular}{lccccc}
\hline Sensitizer & Electrolyte $^{\mathrm{b}}$ & $J_{\mathrm{sc}}\left(\mathrm{mA} / \mathrm{cm}^{2}\right)^{\mathrm{c}}$ & $V_{\mathrm{oc}}(\mathrm{mV})^{\mathrm{c}}$ & $\mathrm{ff}^{\mathrm{c}}$ & $\eta(\%)$ \\
\hline RD-Cou & $\mathrm{Z} 580$ & 8.80 & 650 & 0.68 & 4.24 \\
Z-907 & $\mathrm{Z} 580$ & 11.97 & 650 & 0.68 & 5.20 \\
\hline
\end{tabular}

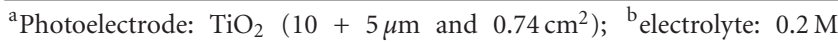
$\mathrm{I}_{2}, 0.5 \mathrm{M}$ guanidinium thiocyanate (GuSCN), and $0.5 \mathrm{M} \mathrm{N}$-methyl benzimidazole $(\mathrm{NMB})$ in a $65 / 35 \mathrm{v} / \mathrm{v} \%$ mixture of 1-propyl-3-methylimidazolium iodide/1-Ethyl-3-methyl-imidazolium tetracyanoborate [PMII/ $\left.\mathrm{EMIB}(\mathrm{CN})_{4}\right] .{ }^{\mathrm{c}}$ Error limits: $J_{\mathrm{sc}}: \pm 0.20 \mathrm{~mA} / \mathrm{cm}^{2}, V_{\mathrm{oc}}= \pm 30 \mathrm{mV}, \mathrm{ff}= \pm 0.03$.

Figure 6 shows the photocurrent-voltage characteristics of RD-Cou and Z-907 using Z-580 as redox electrolyte under 1.0 sun irradiation $\left(1000 \mathrm{~W} / \mathrm{m}^{2}\right)$, and corresponding data are shown in Table 2. The solar-energy-to-electricity conversion efficiency $(\eta)$, under white-light irradiation can be obtained from the following equation:

$$
\eta[\%]=\frac{J_{\mathrm{sc}}\left[\mathrm{Am}^{-2}\right] \cdot V_{\mathrm{OC}}[\mathrm{V}] \times \mathrm{ff}}{I_{0}\left[\mathrm{Wm}^{-2}\right]} \times 100,
$$

where $I_{0}$ is the photon flux (e.g., $1000 \mathrm{~W} \mathrm{~m}^{-2}$ for $1.0 \mathrm{sun}$ ), $J_{\mathrm{sc}}$ is the short-circuit photocurrent density under irradiation,

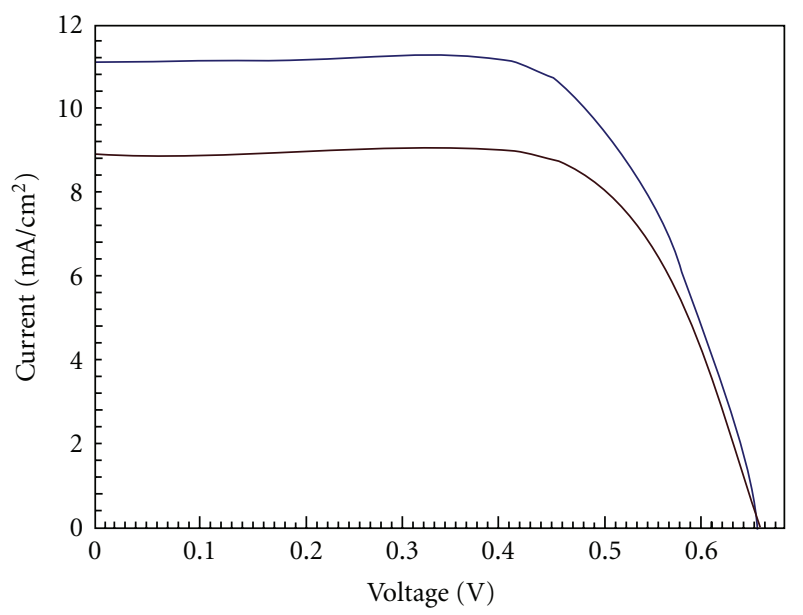

FIguRE 6: Current-voltage characteristics: (brown line) RD-Cou and (blue line) Z-907 using Z-580 redox electrolyte.

$V_{\mathrm{oc}}$ is the open-circuit voltage, and $\mathrm{ff}$ represents the fill factor. We have observed an overall conversion efficiency of $4.24 \%$ under 1.0 sun irradiation $\left(J_{\text {sc }}=8.80 \mathrm{~mA} / \mathrm{cm}^{2}, V_{\text {OC }}\right.$ $=650 \mathrm{mV}, \mathrm{ff}=0.68)$ using RD-Cou as sensitizer. Under similar test cell conditions, the device based on Z-907 sensitizer $\left[J_{\mathrm{sc}}=11.97 \mathrm{~mA} \mathrm{~cm}^{-2}, V_{\mathrm{OC}}=650 \mathrm{mV}\right.$, and $\mathrm{ff}=$ 0.68 ] shows a photovoltaic conversion efficiency of $5.20 \%$. The low efficiency of RD-Cou when compared with that of standard sensitizer Z-907 is probably due to poor hole transport property from coumarin moiety to $\mathrm{Ru}(\mathrm{II})$.

3.3. Thermal Studies. We have examined the thermal stability of new ruthenium(II) polypyridyl sensitizer and compared their thermal stability with that of the standard sensitizer Z-907, using thermogravimetric analysis. Figure 7 shows the thermal behavior of RD-Cou. From the Figure, it is clear that the sensitizer RD-Cou is stable up to $220^{\circ} \mathrm{C}$. The initial weight loss between 200 to $250^{\circ} \mathrm{C}$ is attributed to the removal of the carboxyl group. In contrast, the standard sensitizer Z907 is stable up to $200^{\circ} \mathrm{C}$. 


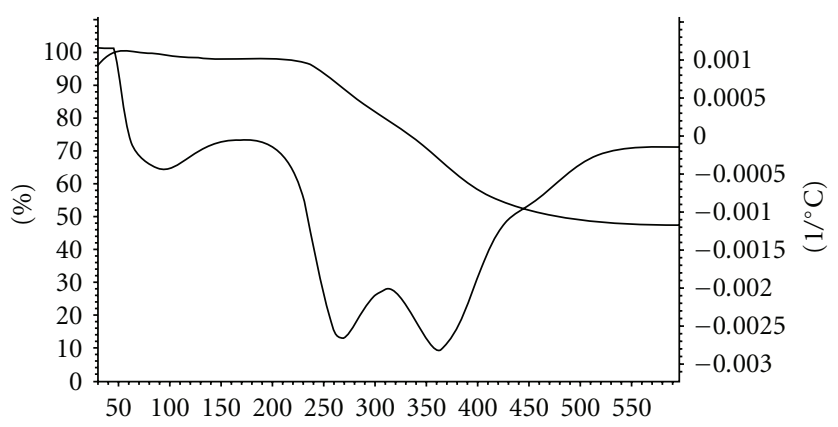

$\left({ }^{\circ} \mathrm{C}\right)$

\begin{tabular}{ll}
\multicolumn{2}{c}{ Conversion } \\
$\left({ }^{\circ} \mathrm{C}\right)$ & $(\%)$ \\
28.56 & 0 \\
91.74 & 1.07 \\
154.92 & 1.79 \\
218.11 & 3.12 \\
281.29 & 12.07 \\
344.47 & 25.83 \\
407.66 & 41.61 \\
470.84 & 48.28 \\
534.02 & 50.73 \\
597.2 & 51.76
\end{tabular}

Figure 7: TG/DTG curves of RD-Cou with heating rate of $10^{\circ} \mathrm{C} \mathrm{min}^{-1}$ under nitrogen.

\section{Conclusions}

In conclusion, we have designed and synthesized a new Coumarin-Ruthenium(II) polypyridyl complex having an extended $\pi$-conjugation. The new complex was completely characterized by elemental analysis, ESI-MS, IR, UV-Visible, and fluorescence spectroscopies as well as cyclic voltammetry. The performance of new sensitizer was tested in dyesensitized solar cells using a durable redox electrolyte and compared with that of standard sensitizer Z-907. The low efficiency of device based on RD-Cou, when compared to Z-907, is probably due to poor hole transport property from coumarin moiety to $\mathrm{Ru}(\mathrm{II})$.

\section{Acknowledgments}

The authors are thankful to the IICT-Aisin Cosmos collaborative project for financial support of this work. L. Giribabu is thankful to the project SR/S1/IC21/2008 for partial financial support of this work. V. K. Singh and Ch. V. Kumar are thankful to Council of Scientific and Industrial Research (CSIR) for a fellowship.

\section{References}

[1] N. Armaroli and V. Balzani, "The future of energy supply: challenges and opportunities," Angewandte ChemieInternational Edition, vol. 46, no. 1-2, pp. 52-66, 2007.

[2] R. F. Service, "Is it time to shoot for the sun?" Science, vol. 309, no. 5734, pp. 548-551, 2005.

[3] A. Hagfeldt, G. Boschloo, L. Sun, L. Kloo, and H. Pettersson, "Dye-sensitized solar cells," Chemical Reviews, vol. 110, no. 11, pp. 6595-6663, 2010.
[4] M. Grätzel, "Recent advances in sensitized mesoscopic solar cells," Accounts of Chemical Research, vol. 42, no. 11, pp. 17881798, 2009.

[5] A. Jäger-Waldau, "Photovoltaics and renewable energies in Europe," Renewable and Sustainable Energy Reviews, vol. 11, no. 7, pp. 1414-1437, 2007.

[6] G. Zhang, H. Bala, Y. Cheng et al., "High efficiency and stable dye-sensitized solar cells with an organic chromophore featuring a binary $\pi$-conjugated spacer," Chemical Communications, no. 16, pp. 2198-2200, 2009.

[7] T. Bessho, S. M. Zakeeruddin, C. Y. Yeh, E. W. G. Diau, and M. Grätzel, "Highly efficient mesoscopic dye-sensitized solar cells based on donor-acceptor-substituted porphyrins," Angewandte Chemie-International Edition, vol. 49, no. 37, pp. 6646-6649, 2010.

[8] L. Giribabu, Ch. Vijaykumar, P. Y. Reddy, J. H. Yum, M. Grätzel, and M. K. Nazeeruddin, "Unsymmetrical extended $\pi$ conjugated zinc phthalocyanine for sensitization of nanocrystalline $\mathrm{TiO}_{2}$ films," Journal of Chemical Sciences, vol. 121, no. 1, pp. 75-82, 2009.

[9] P. Y. Reddy, L. Giribabu, C. Lyness et al., "Efficient sensitization of nanocrystalline $\mathrm{TiO}_{2}$ films by a near-IR-absorbing unsymmetrical zinc phthalocyanine," Angewandte ChemieInternational Edition, vol. 46, no. 3, pp. 373-376, 2007.

[10] M. Grätzel, "Photoelectrochemical cells," Nature, vol. 414, no. 6861, pp. 338-344, 2001.

[11] M. K. Nazeeruddin, P. Péchy, T. Renouard et al., "Engineering of efficient panchromatic sensitizers for nanocrystalline $\mathrm{TiO}_{2}$ based solar cells," Journal of the American Chemical Society, vol. 123, no. 8, pp. 1613-1624, 2001.

[12] M. K. Nazeeruddin, A. Kay, I. Rodicio et al., "Conversion of light to electricity by cis- $\mathrm{X}_{2}$ bis $\left(2,2^{\prime}\right.$-bipyridyl- $4,4^{\prime}$ dicarboxylate)ruthenium(II) charge-transfer sensitizers ( $\mathrm{X}=$ $\mathrm{Cl}^{-}, \mathrm{Br}^{-}, \mathrm{I}^{-}, \mathrm{CN}^{-}$, and $\left.\mathrm{SCN}^{-}\right)$on nanocrystalline $\mathrm{TiO}_{2}$ electrodes," Journal of the American Chemical Society, vol. 115, no. 14, pp. 6382-6390, 1993.

[13] B. O’Regan and M. Grätzel, "A low-cost, high-efficiency solar cell based on dye-sensitized colloidal $\mathrm{TiO}_{2}$ films," Nature, vol. 353, no. 6346, pp. 737-740, 1991.

[14] P. Wang, S. M. Zakeeruddin, J. E. Moser, M. K. Nazeeruddin, T. Sekiguchi, and M. Grätzel, "A stable quasi-solid-state dyesensitized solar cell with an amphiphilic ruthenium sensitizer and polymer gel electrolyte," Nature Materials, vol. 2, no. 6, pp. 402-407, 2003.

[15] D. Kuang, P. Wang, S. Ito, S. M. Zakeeruddin, and M. Grätzel, "Stable mesoscopic dye-sensitized solar cells based on tetracyanoborate ionic liquid electrolyte," Journal of the American Chemical Society, vol. 128, no. 24, pp. 7732-7733, 2006.

[16] P. Wang, C. Klein, R. Humphry-Baker, S. M. Zakeeruddin, and M. Grätzel, "A high molar extinction coefficient sensitizer for stable dye-sensitized solar cells," Journal of the American Chemical Society, vol. 127, no. 3, pp. 808-809, 2005.

[17] P. Wang, S. M. Zakeeruddin, J. E. Moser et al., "Stable new sensitizer with improved light harvesting for nanocrystalline dye-sensitized solar cells," Advanced Materials, vol. 16, no. 20, pp. 1806-1811, 2004.

[18] L. Giribabu, T. Bessho, M. Srinivasu et al., "A new family of heteroleptic ruthenium polypyridyl complexes for sensitization of nanocrystalline $\mathrm{TiO}_{2}$ Flms," Dalton Transactions, vol. 40, pp. 4497-4504, 2011.

[19] L. Giribabu, V. K. Singh, M. Srinivasu et al., "Synthesis and photoelectrochemical chacterization of a high molar 
extinction coefficient heteroleptic ruthenium(II) complex," Journal of Chemical Science. In press.

[20] L. Giribabu, Ch. Vijaykumar, C. S. Rao et al., "High molar extinction coefficient amphiphilic ruthenium sensitizers for efficient and stable mesoscopic dye-sensitized solar cells," Energy and Environmental Science, vol. 2, no. 7, pp. 770-773, 2009.

[21] K. J. Jiang, N. Masaki, J. B. Xia, S. Noda, and S. Yanagida, "A novel ruthenium sensitizer with a hydrophobic 2-thiophen2-yl-vinyl- conjugated bipyridyl ligand for effective dye sensitized $\mathrm{TiO}_{2}$ solar cells," Chemical Communications, no. 23, pp. 2460-2462, 2006.

[22] C. Y. Chen, N. Pootrakulchote, S. J. Wu et al., "New ruthenium sensitizer with carbazole antennas for efficient and stable Thin-film Dye-sensitized solar cells," Journal of Physical Chemistry C, vol. 113, no. 48, pp. 20752-20757, 2009.

[23] K. Hara, M. Kurashige, Y. Dan-Oh et al., "Design of new coumarin dyes having thiophene moieties for highly efficient organic-dye-sensitized solar cells," New Journal of Chemistry, vol. 27, no. 5, pp. 783-785, 2003.

[24] K. Hara, K. Sayama, Y. Ohga, A. Shinpo, S. Suga, and H. Arakawa, "A coumarin-derivative dye sensitized nanocrystalline $\mathrm{TiO}_{2}$ solar cell having a high solar-energy conversion efficiency up to 5.6\%," Chemical Communications, no. 6, pp. 569-570, 2001.

[25] H. Zabri, I. Gillaizeau, C. A. Bignozzi et al., "Synthesis and comprehensive characterizations of new cis- $\mathrm{RuL}_{2} \mathrm{X}_{2}(\mathrm{X}=\mathrm{CI}$, $\mathrm{CN}$, and NCS) sensitizers for nanocrystalline $\mathrm{TiO}_{2}$ solar cell using bis-phosphonated bipyridine ligands (L)," Inorganic Chemistry, vol. 42, no. 21, pp. 6655-6666, 2003.

[26] K. Hara, Z. S. Wang, T. Sato et al., "Oligothiophene-containing coumarin dyes for efficient dye-sensitized solar cells," Journal of Physical Chemistry B, vol. 109, no. 32, pp. 15476-15482, 2005.

[27] W. S. Wadsworth and W. D. Emmons, "The utility of phosphonate carbanions in olefin synthesis," Journal of the American Chemical Society, vol. 83, no. 7, pp. 1733-1738, 1961.

[28] M. J. Frisch, G. W. Trucks, H. B. Schlegel et al., Gaussian 03, Revision D.01, Gaussian, Inc., Wallingford, Conn, USA, 2004.

[29] L. Giribabu, Ch. Vijaykumar, V. G. Reddy et al., "Unsymmetrical alkoxy zinc phthalocyanine for sensitization of nanocrystalline $\mathrm{TiO}_{2}$ films," Solar Energy Materials and Solar Cells, vol. 91, no. 17, pp. 1611-1617, 2007.

[30] L. Giribabu, Ch. Vijaykumar, and P. Y. Reddy, "Porphyrinrhodanine dyads for dye sensitized solar cells," Journal of Porphyrins and Phthalocyanines, vol. 10, no. 8, pp. 1007-1016, 2006.

[31] L. Giribabu, M. Chandrasekheram, M. L. Kantham et al., "Conjugated organic dyes for dye-sensitized solar cells," Indian Journal of Chemistry-Section A, vol. 45, no. 3, pp. 629-634, 2006.

[32] M. K. Nazeeruddin, R. Splivallo, P. Liska, P. Comte, and M. Grätzel, "A swift dye uptake procedure for dye sensitized solar cells," Chemical Communications, vol. 9, no. 12, pp. 14561457, 2003.

[33] N. Kopidakis, N. R. Neale, and A. J. Frank, "Effect of an adsorbent on recombination and band-edge movement in dyesensitized $\mathrm{TiO}_{2}$ solar cells: evidence for surface passivation," Journal of Physical Chemistry B, vol. 110, no. 25, pp. 1248512489, 2006. 

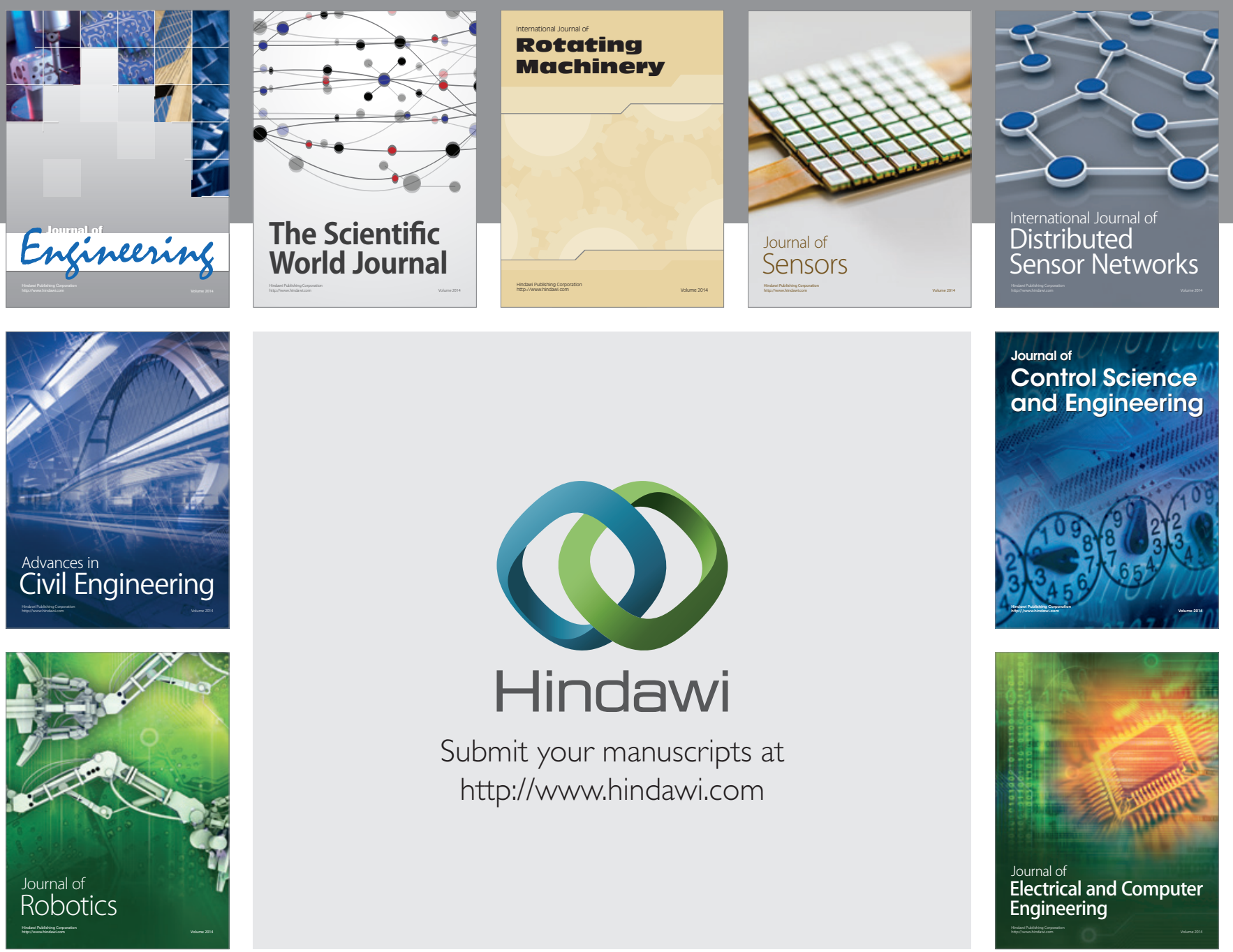

Submit your manuscripts at

http://www.hindawi.com
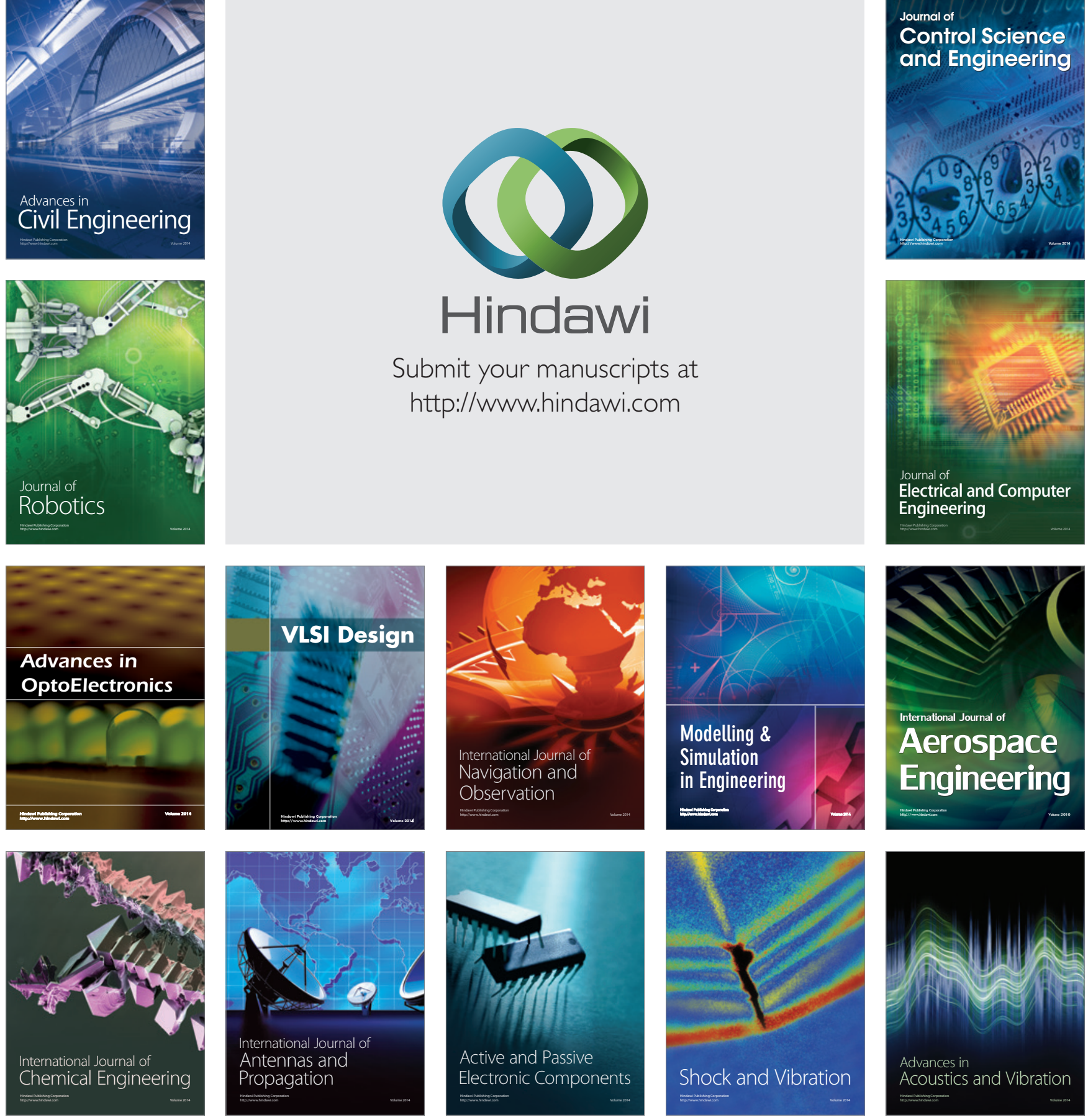